DOI: https://doi.org/10.24123/jbt.v3i02.2508

\title{
ANALISIS PEKERJAAN DAN PERENCANAAN SUMBER DAYA MANUSIA SERTA PENGARUHNYA TERHADAP METODE REKRUTMEN
}

\author{
Novie P. Marhaeni \\ Secretary Study Program, PoliteknikUbaya, Surabaya \\ Email: n.marhaeni@gmail.com
}

\begin{abstract}
Human resources and jobs are an inseparable unit in a company. Both go hand in hand and have high dependency. Company management needs to do a job analysis along with human resource planning that will fill the formation or do the work. Therefore, job analysis and HR planning provide direction for management to determine the right method in the recruitment process. Thus, they can get the right people to fill the right position too. This article aims to examine and explain the effect of job analysis and HR planning on recruitment methods. With the literature study conducted, it was concluded that both the job analysis and HR planning variables have a significant influence on the recruitment method.
\end{abstract}

Keywords: job analysis, HR planning, recruitment methods.

\section{Pendahuluan}

Dalam suatu organisasi atau perusahaan, Sumber Daya Manusia (SDM) mempunyai peran yang sama pentingnya dengan pekerjaan itu sendiri. Di samping itu, SDM merupakan faktor penentu bagi keberhasilan organisasi atau perusahaan tersebut. SDM dengan kompetensi yang sesuai dengan kebutuhan pekerjaan, secara efektif akan menunjang kelancaran aktivitas pekerjaan. Oleh karena itu, kompetensi menjadi salah satu aspek yang menentukan keberhasilan organisasi atau perusahaan. Dengan memiliki SDM berkompetensi tinggi, secara langsung akan memengaruhi tingkat kinerja perusahaan.

Manajemen perusahaan harus mengetahui hal apa yang dibutuhkan oleh suatu pekerjaan dan kemudian menetapkan orang-orang dengan kualifikasi tertentu yang harus direkrut untuk melakukan pekerjaan tersebut. Kesalahan dalam menganalisis pekerjaan akan berdampak pada seluruh upaya peningkatan sumber daya manusia menjadi tidak bermanfaat (Bangun, 2012). Untuk itu, manajemen harus melakukan analisis pekerjaan sebelum menentukan prosedur seleksi, penilaian, atau kriteria lain yang diperlukan (Reed et al., 2010). 
Sebagai langkah awal dari kegiatan manajemen sumber daya manusia, analisis pekerjaan sangat berkaitan erat dengan kegiatan pengadaan, pelatihan, dan pengembangan, hingga masalah keselamatan dan kesehatan tenaga kerja (Bangun, 2012). Selanjutnya disebutkan bahwa pekerjaanpekerjaan dalam organisasi perlu dianalisis terlebih dulu agar dapat dikerjakan secara efektif dan efisien, sehingga tujuan organisasi dapat tercapai. Analisis pekerjaan merupakan prosedur dalam menentukan tugas-tugas dan hakekat pekerjaan serta kualifikasi orang yang perlu diangkat untuk mengerjakannya.

Wirawan (2015) mendefinisikan analisis pekerjaan sebagai penelitian untuk mengumpulkan informasi mengenai pekerjaan untuk dipergunakan dalam aktivitas manajemen organisasi. Sedangkan menurut Desler (1982), analisis pekerjaan adalah prosedur yang digunakan untuk menentukan tugas dari posisi dalam perusahaan dan karakteristik orang yang dipekerjakan untuk melaksanakan tugas tersebut. Hampir pada setiap tindakan yang berkaitan dengan personel membutuhkan pengetahuan mengenai apa yang diminta oleh suatu pekerjaan dan ciri-ciri manusia yang dibutuhkan seseorang untuk melakukan pekerjaan tersebut dengan baik.

Analisis pekerjaan adalah metode unik yang didasarkan pada hasil yang didukung oleh data. Dalam melakukan analisis pekerjaan secara tepat, dapat memberikan informasi yang cukup untuk mengembangkan sumber daya yang dapat diakses dan digunakan oleh manajemen untuk merancang evaluasi kinerja yang berfokus pada pengembangan bakat (Gatewood et al., 2015). Selain itu, analisis pekerjaan juga menetapkan standar seleksi yang dapat digunakan untuk mengetahui kemajuan dan mengevaluasi kinerja (Reed et al., 2010). Pada uraian tentang langkah dalam melakukan analisis pekerjaan terhadap suatu pekerjaan yang dikemukakan oleh Desler (1982), di antaranya adalah menganalisis pekerjaan secara nyata dan mengembangkan deskripsi pekerjaan dan spesifikasi pekerjaan. Artinya bahwa aktivitas analisis pekerjaan mengarah pada bagaimana strategi dalam menemukan tenaga kerja yang tepat untuk melakukan suatu pekerjaan yang telah ditentukan. Tujuan dari analisis pekerjaan ini adalah untuk memberikan uraian dan spesifikasi suatu pekerjaan tertentu (Bangun, 2012). Tujuan lain adalah untuk menentukan sistem perekrutan karyawana dalam perusahaan, penentuan struktur organisasi, yang semuanya dilakukan untuk mencapai tujuan perusahaan.

Berkaitan dengan pengadaan tenaga kerja, Backstrom dan Bjorklund (2017) merekomendasikan bahwa segala sesuatu mulai dari analisis kebutuhan, analisis pekerjaan, pemilihan instrumen seleksi, penggunaan instrumen dan evaluasi hasil, pengumpulan informasi, pengambilan keputusan, hingga evaluasi proses itu sendiri, harus ditandai secara sistematis dengan pendekatan analitis. Selanjutnya dijelaskan artinya bahwa proses seleksi yang baik harus melibatkan analisis pekerjaan yang cermat, menghubungkan konten pekerjaan dengan kriteria spesifik untuk penilaian, mengumpulkan informasi dengan metode yang rumit (wawancara terstruktur, makalah aplikasi yang ditimbang dan tes pengetahuan yang berbeda) dan mengambil keputusan berdasarkan algoritma transparan untuk menggabungkan data yang dikumpulkan.

Kemudian bagaimana perencanaan SDM dapat memberikan pengaruh terhadap metode rekrutmen? Dalam upaya menemukan korelasi antara analisis pekerjaan dan perencanaan SDM serta pengaruhnya terhadap metode rekrutmen, penulis berusaha untuk melakukan studi literatur dari hasil penelitian terdahulu dan teori-teori terkait topik di atas. Adapun tujuan dari artikel ini adalah untuk menjelaskan pengaruh analisis pekerjaan dan perencanaan SDM terhadap metode rekrutmen. Perencanaan SDM mendorong manajemen untuk menetapkan strategi guna memperoleh, memanfaatkan, mengembangkan, dan mempertahankan SDM sesuai dengan kebutuhan perusahaan saat ini dan pengembangannya di masa yang akan datang. Dengan 
menggunakan perencanaan strategis, manajemen bertujuan untuk memiliki jumlah dan jenis karyawan yang tepat, di tempat yang tepat pada waktu yang tepat, serta melakukan tindakan yang menghasilkan manfaat jangka panjang bagi individu dan organisasi.

Salah satu tahapan dalam proses perencanaan SDM adalah peramalan kebutuhan SDM, di mana hal ini meliputi jumlah staf yang dibutuhkan, pekerjaan yang perlu diisi, dan keterampilan yang dibutuhkan (Ulferts et al., 2009). Dalam penelitiannya, Ulferts et al. (2009) mengungkapkan bahwa ketika memperkirakan kemungkinan permintaan akan sumber daya manusia, juga penting untuk menilai tantangan yang akan dimiliki institusi dalam memenuhi kebutuhan kepegawaiannya berdasarkan lingkungan eksternal. Penilaian ini harus fokus pada bagaimana lingkungan eksternal dapat memengaruhi kebutuhan SDM.

Sementara itu, dalam praktik organisasi, perencanaan SDM sangat penting untuk mendapatkan tenaga kerja yang mumpuni dan sesuai dengan kebutuhan pekerjaan yang ada. Perencanaan SDM sendiri merupakan suatu proses melakukan prediksi terhadap keadaan dan kebutuhan SDM suatu organisasi di masa sekarang dan masa yang akan datang agar organisasi tidak kekurangan atau kelebihan jumlah SDM dengan kualitas tertentu untuk mencapai tujuan organisasi (Wirawan, 2015). Banyak ditemui bahwa perusahaan dirugikan secara materiil maupun nonmateriil karena adanya kesalahan dalam perekrutan tenaga kerja. Tetapi dengan perencanaan SDM yang tepat akan berdampak pada kinerja karyawan, dan selanjutnya dapat memengaruhi pula kinerja perusahaan di masa yang akan datang.

Sehubungan dengan analisis pekerjaan yang dilakukan, maka perencanaan SDM dalam perusahaan berkaitan dengan penyediaan tenaga kerja akan dapat direncanakan pula secara sistematis. Zainal dkk. (2014) menyebutkan beberapa keuntungan bagi perusahaan yang menerapkan perencanaan SDM, sebagai berikut.

1. Integrasi yang strategis antara permintaan dan jumlah staf yang ada.

2. Pemanfaatan SDM yang tersedia secara efektif.

3. Persaingan SDM dan sasaran perusahaan masa depan secara tepat guna.

4. Hemat secara ekonomi dalam penerimaan para pegawai baru.

5. Memperluas informasi SDM sesuai dengan kegiatan SDM dan unit organisasi lain.

6. Permintaan dalam jumlah besar pada pasar tenaga kerja lokal akan terpenuhi.

7. Koordinasi program SDM dan kebutuhan yang tersedia.

Dengan perencanaan SDM tersebut, maka perusahaan dapat menetapkan suatu strategi yang tepat dalam upaya mendapatkan tenaga kerja, baik secara kuantitas maupun secara kualitas. Melalui estimasi atau perkiraan kebutuhan tenaga kerja, baik dari segi jumlah, keterampilan, kompetensi, pengalaman kerja, dan aspek lainnya, dapat dipastikan perusahaan akan mampu mengatasi permasalahan kesenjangan antara kebutuhan dan ketersediaan SDM. Karyawan yang melakukan pekerjaan sesuai dengan kompetensinya akan memiliki kinerja yang baik dan menguntungkan perusahaan, karena mereka dapat bekerja secara efektif dan efisien. Hal ini akan membantu manajemen dalam melakukan perekrutan dan proses seleksi untuk mendapatkan SDM terbaik.

Menurut C-T Sua dan T-M Yang (2015), rekrutmen dan seleksi adalah proses mencari dan memperoleh pelamar kerja potensial dari kelompok sasaran, kampus, atau area tertentu, yang memungkinkan pengusaha untuk memilih kandidat yang paling cocok untuk mengisi lowongan pekerjaan. Proses pelaksanaan rekrutmen dalam perusahaan tentu menerapkan suatu metode di 
dalamnya, tetapi dalam praktiknya tidak ada pendekatan terbaik atau prosedur yang diterima secara umum tentang cara merekrut dan memilih kandidat karena pengusaha yang berbeda memiliki metode perekrutan dan seleksi yang berbeda tergantung pada operasi, ukuran, dan kebutuhan mereka.

Metode rekrutmen adalah suatu cara yang paling tepat dipilih perusahaan untuk diterapkan. Setiap perusahaan memiliki dan menerapkan metode yang berbeda-beda sesuai dengan kebutuhannya dan akan berpengaruh besar terhadap banyaknya lamaran yang masuk ke dalam perusahaan. Menurut Hasibuan (2010) metode rekrutmen calon karyawan baru ada 2, yaitu metode tertutup dan metode terbuka. Di sisi lain, dalam pelaksanannya, rekrutmen memiliki dua sumber untuk mendapatkan SDM, yaitu sumber internal dan sumber eksternal. Sumber interal meliputi: a. Penempatan pekerjaan; b. Inventarisasi keahlian; c. Penawaran pekerjaan; d. Rekomendasi karyawan. Sedangkan sumber eksternal meliputi: a. Institusi pendidikan; b. Iklan; c. Agen pemerintah; d. Agen swasta; e. Perusahaan pencari tenaga eksekutif.

Menurut Kasmir (2016), beberapa cara atau metode yang digunakan untuk menarik minat pelamar agar datang melamar, yaitu: 1) informasi yang disajikan; 2) format lamaran; 3) pemilihan media untuk membuat lowongan kerja; 4) menempelkan brosur; 5) waktu yang diberikan tidak terlalu singkat. Secara umum, metode rekrutmen akan menentukan orang yang tepat untuk menduduki posisi dan melakukan pekerjaan yang tepat atau sesuai dengan kompetensinya.

\section{Kerangka Konseptual}

Kerangka konseptual ini dirumuskan dengan mengacu pada penelitian terdahulu, di mana hal tersebut menentukan hubungan antar variabel yang dibangun sebagaimana tampak pada Gambar 1 berikut.

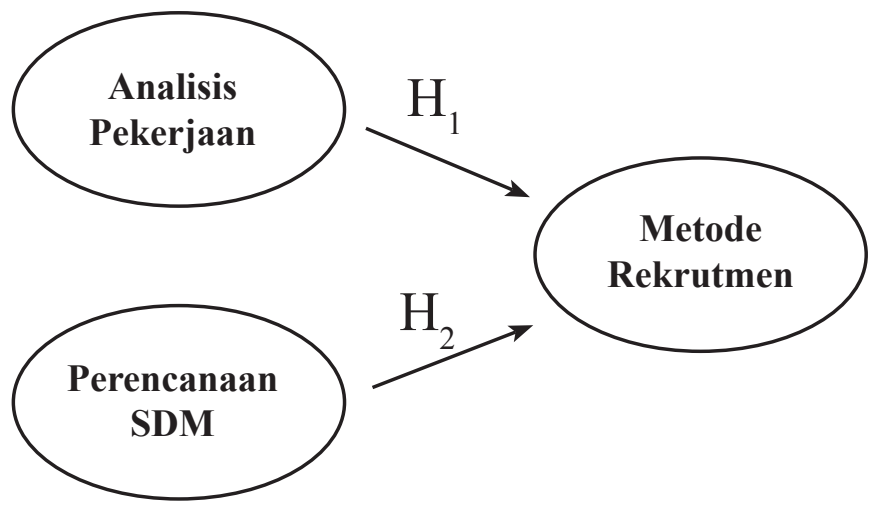

Gambar 1 Kerangka Konseptual

Berdasarkan uraian dan penjelasan secara teoritis dan empiris tentang model konseptual di atas, maka dirumuskan hipotesis sebagai berikut.

$\mathrm{H}_{1}$ : Analisis pekerjaan berpengaruh terhadap metode rekrutmen

$\mathrm{H}_{2}$ : Perencanaan Sumber Daya Manusia (SDM) berpengaruh terhadap metode rekrutmen 


\section{Metodologi Penelitian}

Penelitian ini merupakan penelitian deskriptif berdasarkan studi literatur dan dari penelitian terdahulu. Dalam penelitian ini dilakukan investigasi pada pengaruh analisis pekerjaan terhadap metode rekrutmen $\left(\mathrm{H}_{1}\right)$, pengaruh perencanaan SDM terhadap metode rekrutmen $\left(\mathrm{H}_{2}\right)$.

\section{Pembahasan}

\section{Pengaruh Analisis Pekerjaan terhadap Metode Rekrutmen}

Proses analisis pekerjaan penting sekali dilakukan untuk memberi arah bagi manajemen dalam menata dan mengelola SDM. Selain untuk pengelolaan SDM, berdasarkan analisis pekerjaan tersebut dapat diketahui spesifikasi pekerjaan yang diperlukan. Selanjutnya manajemen dapat merancang kegiatan strategis dalam upaya mendapatkan SDM yang sesuai dengan kebutuhan pekerjaan tersebut. Pada tahap awal adalah aktivitas atau proses rekrutmen yang tepat untuk mencapai sasaran yang tepat pula. Proses rekrutmen haruslah dilakukan secara jelas, tegas, dan transparan. Maka dapat dikatakan bahwa kegiatan yang dimulai dengan analisis pekerjaan yang tepat akan berdampak pada keberhasilan proses selanjutnya. Sementara itu, Rencana rekrutmen membahas kekurangan tenaga kerja atau redudansi karena rencana bisnis berfluktuasi secara dinamis; namun, kegiatan rekrutmen dipengaruhi oleh tren musiman (C-T Sua dan T-M Yang, 2015).

Seperti halnya yang disampaikan oleh Backstrom dan Bjorklund (2017), di mana analisis pekerjaan membuat proses rekrutmen menjadi lebih transparan. Yildiz dan Özer (2017), dalam penelitiannya juga menyebutkan bahwa dengan mengembangkan dan menyiapkan uraian pekerjaan personel kantor yang bekerja di pelabuhan peti kemas, bertujuan untuk menghasilkan sumber sampel untuk proses rekrutmen yang dapat diuntungkan oleh manajer SDM atau spesialis pelabuhan. Sementara itu, penelitian Ashraf (2017) menyimpulkan bahwa proses perekrutan sektor publik didapati cacat karena analisis pekerjaan yang buruk. Mereka tidak membuat deskripsi pekerjaan yang tepat dan tugas karyawan tidak sesuai dengan deskripsi pekerjaan yang diberikan, yang pada akhirnya memengaruhi kinerja organisasi sektor publik di Pakistan. Dari hasil penelitian terdahulu tersebut menunjukkan bahwa analisis pekerjaan memiliki pengaruh yang signifikan terhadap metode rekrutmen.

\section{Pengaruh Perencanaan SDM terhadap Metode Rekrutmen}

Berbeda dengan analisis pekerjaan, di mana aktivitas berfokus pada perencanaan atau perancangan suatu pekerjaan, maka perencanaan SDM mengarahkan manajemen untuk menentukan orang-orang yang tepat yang akan melaksanakan pekerjaan tersebut. Selain itu, manajemen juga perlu mempertimbangkan ketersediaan SDM yang ada di perusahaan, sehingga aktivitas kerja dapat dipastikan terus berlangsung dengan baik. Jumlah SDM yang pergi, baik karena pensiun atau pun meninggalkan pekerjaan karena berbagai alasan, jumlah SDM yang tinggal, dan jumlah SDM yang masuk haruslah dalam perhitungan yang tepat supaya produktivitas kerja tetap berjalan stabil.

Dalam penelitiannya, C-T Sua dan T-M Yang (2015) menyebutkan bahwa rencana rekrutmen untuk perusahaan teknologi tinggi didasarkan pada rencana SDM. Dalam perencanaan SDM, perusahaan perlu menetapkan tujuan, baik jangka pendek maupun jangka panjang. Hal ini diperlukan untuk menentukan apakah jumlah pelamar atau jumlah karyawan baru dapat memenuhi tujuan organisasi atau perusahaan yang telah ditetapkan (Ulferts, 2009). Dalam tulisannya, Momin dan Mishra (2015) menjelaskan bahwa rekrutmen dan seleksi merupakan komponen utama dalam 
perencanaan strategis Sumber Daya Manusia untuk mencapai akurasi keberhasilan implementasi dari perencanaan tersebut. Proses rekrutmen yang kuat dalam organisasi akan menguntungkan bagi praktik sosialisasi yang efektif dan dapat meningkatkan komitmen individu terhadap perusahaan (Aisbett dan Hoye, 2015).

Metode rekrutmen dari sumber internal maupun eksternal, keduanya memiliki kekuatan yang dapat saling melengkapi. Rekrutmen dari sumber eksternal dewasa ini lebih banyak dilakukan melalui media sosial, iklan di internet, dan juga melalui surat kabar, dibandingkan dilakukan secara manual dengan memasang flyer atau proster di tempat-tempat umum. Weerakoon (2016) dalam penelitiannya pada perusahaan sport menjelaskan bahwa rekrutmen karyawan dari perguruan tinggi adalah metode dengan banyak manfaat, karena universitas adalah sumber terbaik untuk menemukan profesional muda. Untuk posisi strategis, sumber internal memberikan keuntungan lebih terutama untuk product knowledge dan efisiensi biaya. Dari uraian tersebut dapat disimpulkan bahwa perencanaan SDM yang efektif memberikan pengaruh terhadap metode yang dilakukan dalam merekrut orang-orang sesuai dengan kebutuhan pekerjaan.

\section{Simpulan}

Sumber Daya Manusia memiliki peran sangat penting dalam suatu perusahaan, sehingga menjadi sesuatu yang mendesak bagi manajemen untuk melakukan perencanaan, baik terhadap pekerjaan maupun dalam pemetaan ketersediaan karyawan yang ada. Dari studi literatur yang dilakukan dalam artikel ini, diperoleh informasi bahwa analisis pekerjaan dan perencanaan SDM keduanya memberikan kontribusi besar berupa informasi akan kebutuhan spesifikasi pekerjaan. Selanjutnya manajemen dapat mengetahui orang-orang dengan talenta atau kompetensi seperti apa yang akan direkrut. Dengan perencanaan yang efektif terhadap SDM serta melakukan analisis pekerjaan, akan memudahkan manajemen dalam menentukan metode yang tepat dalam merekrut orang-orang bertalenta yang akan menjalankan pekerjaan tersebut.

Berdasarkan pembahasan tentang studi di atas dapat digambarkan bahwa analisis pekerjaan dan perencanaan Sumber Daya Manusia yang efektif memberikan pengaruh terhadap bagaimana cara rekrutmen yang tepat dapat diterapkan oleh perusahaan untuk mendapatkan karyawan yang tepat pula. Adapun manfaat dari artikel ini dapat memberikan kontribusi berupa informasi atau pun referensi bagi akademisi maupun para peneliti yang ingin mengembangkan keilmuan di bidang SDM, khususnya dengan variabel yang ada pada penelitian ini. Penelitian yang akan dilakukan dapat pula dikembangkan dengan menggunakan atau menambahkan variabel lain yang mendukung.

\section{Daftar Pustaka}

Ashraf, Junaid. 2017. Examining the Public Sector Recruitment and Selection, in Relation to Job Analysis in Pakistan. Cogent Social Sciences, Vol. 3(1).

Aisbett, L., dan R. Hoye. 2015. Human Resource Management Practices to Support Sport Event Volunteers. Asia Pacific Journal of Human Resources, Vol. 53(3), p. 351-369.

Backstrom, Martin dan Fredrik Bjorklund. 2017. Increasing Systematicity Leads to Better Selection Decisions: Evidence from A Computer Paradigm for Evaluating Selection Tools. Journal of PLOS ONE. https://doi.org/10.1371/journal.phone.0178276.

Bangun, Wilson. 2012. Manajemen Sumber Daya Manusia. Jakarta: Erlangga. 
Campbell, J. P. (1990). Modeling the performance prediction problem in industrial and organizational psychology. In M. D. Dunnette \& L. M. Hough (Eds.), Handbook of industrial and organizational psychology (Vol. 1, pp. 687-732). Palo Alto: Consulting Psychologists Press.

Campbell, J. P. (1990). Modeling the performance prediction problem in industrial and organizational psychology. In M. D. Dunnette \& L. M. Hough (Eds.), Handbook of industrial and organizational psychology (Vol. 1, pp.687-732). Palo Alto: Consulting Psychologists Press.

Chao-Ton Sua dan Tsung-Ming Yang. 2015. Hoshin Kanri Planning Process in Human Resource Management: Recruitment in a High-Tech Firm. Total Quality Management, Vol. 26, No. 2, p. 140-156.

Dessler, G. 1982. Organization and Management. Virginia: Reston Publishing Company Inc.

Gatewood, Robert, Hubert S. Feild dan Murray Barrick. 2015. Human Resource Selection. USA: Chengage Learning.

Hasibuan, Malayu S.P. 2010. Manajemen Sumber Daya Manusia. Edisi Revisi, Cetakan ketujuh. Jakarta: Bumi Aksara.

Kasmir. 2016. Manajemen Sumber Daya Manusia (Teori dan Praktik). Jakarta: Rajawali Pers.

Momin, Weena Y.M. dan Kushendra Mishra. 2015. HR Analytics as a Strategic Workforce Planning. International Journal of Applied Research, 1(4), p. 258-260.

Reed, M. S., A. C. Evely, G. Cundill, I. Fazey, J. Glass, A. Laing, J. Newig, B. Parrish, C. Prell, C. Raymond, and L. C. Stringer. 2010. What is Social Learning? Ecology and Society, Vol. 15(4).

Ulferts, Gregory, P. Wirtz, dan E. Peterson. 2009. Strategic Human Resource Planning In Academia. American Journal of Business Education, Vol. 2(7).

Weerakoon, Ranjan K. 2016. Human Resource Management in Sports: A Critical Review of its Importance and Pertaining Issues. Physical Culture and Sport Studies and Research, Vol. 69.

Wirawan. 2015. Manajemen Sumber Daya Manusia Indonesia: Teori, Psikologi, Hukum Ketenagakerjaan, Aplikasi dan Penelitian (Aplikasi dalam Organisasi Bisnis, Pemerintahan dan Pendidikan). Jakarta: PT RajaGrafindo Persada.

Yildiz, R.Ö. dan Özer Çaylan, D. 2017. A Critical Approach to the Job Analysis Practices of Turkish Container Ports. Gazi Journal of Economics and Business, 3(3), p. 17 -37.

Zainal, Veithzal Rivai dkk. 2014. Manajemen Sumber Daya Manusia untuk Perusahaan: dari Teori ke Praktik, Edisi ke-3. Jakarta: PT RajaGrafindo Persada. 
